\title{
FG 7I42 Specifically Reduces Meal Size and the Rate and Regularity of Sustained Feeding in Female Rats: Evidence that Benzodiazepine Inverse Agonists Reduce Food Palatability
}

\author{
Pietro Cottone ${ }^{*, 1,2,4}$, Valentina Sabino ${ }^{1,4}$, Luca Steardo ${ }^{2}$ and Eric P Zorrilla*,1,3 \\ 'Committee on the Neurobiology of Addictive Disorders, The Scripps Research Institute, La Jolla, CA, USA; ${ }^{2}$ Department of Human Physiology and \\ Pharmacology, University of Rome La Sapienza, Rome, Italy; ${ }^{3}$ The Harold L. Dorris Neurological Research Center, The Scripps Research Institute, \\ La Jolla, CA, USA
}

\begin{abstract}
Benzodiazepine receptor inverse agonists reduce food intake in males, but their actions in females, in whom stress-related eating disorders are more common, as well as their behavioral mode of action remain unclear. The consummatory effects of benzodiazepine receptor ligands have alternately been hypothesized to reflect changes in the hedonic evaluation of food or secondary effects of anxietyrelated or cognitive properties. To test the anorectic mode of action of benzodiazepine inverse agonists, the effects of FG 7 I 42 on feeding microstructure were studied in nondeprived female Wistar rats $(n=32)$. Microstructure analysis used a novel meal definition that recognizes prandial drinking. On pharmacologically synchronized diestrus I, rats were pretreated ( -30 min dark onset) with the benzodiazepine partial inverse agonist FG $7 / 42$ (i.p. $0,3.75,7.5,15 \mathrm{mg} / \mathrm{kg}$ ) in a between-subjects design. FG 7/42 delayed the onset of ( $16-541 \%$ ), decreased the amount eaten (36-52\%) and drunk (63-87\%), and reduced the time spent drinking (59-87\%) within the first nocturnal meal. Dose-dependent incremental anorexia continued $6 \mathrm{~h}$ into the dark cycle, whereas FG 7 I 42 did not suppress the quantity, duration or rate of drinking past the first meal. Treated rats ate smaller meals ( 17-42\%) of normal duration. This reflected that FG 7 I 42 slowed feeding within meals (9-38\%) by decreasing the regularity and maintenance of feeding from pellet-to-pellet. FG 7/42 did not influence postprandial satiety; meal frequency and inter-meal intervals were unaffected. FG 7|42 anorexia was blocked by the benzodiazepine receptor antagonist flumazenil in a $2: 1$ molar ratio $(n=17$ rats). The very early, nonspecific $(+10$ min), but not subsequent $(2.5,4.5 \mathrm{~h}$ ) feeding-specific phase, of FG 7 I 42 anorexia was mirrored by anxiogenic-like behavior in FG 7/42-treated (7.5 mg/ $\mathrm{kg})$ female rats $(n=48)$ in the elevated plus-maze. Thus, benzodiazepine receptor inverse agonists preferentially lessen the maintenance of feeding in female rats, effects opposite to those of palatable food.

Neuropsychopharmacology (2007) 32, I069-1081. doi:I0.1038/sj.npp. I301229; published online I November 2006
\end{abstract}

Keywords: benzodiazepine receptor; meal pattern or microstructure; palatability; food intake or feeding; GABA; obesity

\section{INTRODUCTION}

Food intake is motivated by both homeostatic and nonhomeostatic mechanisms. Brain benzodiazepine receptors have been proposed to control food intake by changing the nonhomeostatic hedonic evaluation of food (for review, see Cooper, 2005), a function for which they are receiving renewed attention in the current era of obesity and

\footnotetext{
* Correspondence: Dr P Cottone or Dr EP Zorrilla, Committee on the Neurobiology of Addictive Disorders, SP30-2400, The Scripps Research Institute, 10550 N. Torrey Pines Road, La Jolla, CA 92037, USA, Tel: + I 858784 7464, Fax: + I 8587847405 ,

E-mail: cottone@scripps.edu or ezorrilla@scripps.edu

${ }^{4}$ These authors equally contributed to this work.

Received 3 March 2006; revised 22 August 2006; accepted 29 August 2006

Online publication: 15 September 2006 at http://www.acnp.org/ citations/Npp09| 506060 I47/default.pdf
}

disorders of binge eating. The benzodiazepine receptor is an allosteric binding site at the conjunction of $\alpha$ and $\gamma 2$ subunits (Rudolph and Möhler, 2004) of the type A gammaaminobutyric acid receptor $\left(\mathrm{GABA}_{\mathrm{A}}\right)$. Benzodiazepines modulate ion flux through the $\mathrm{GABA}_{\mathrm{A}}$-gated $\mathrm{Cl}^{-}$-channel ionophore complex by altering the kinetics of channel opening and are used clinically as anxiolytic, sedativehypnotic, and anticonvulsant drugs (Chouinard, 2004; O'Brien, 2005). The effects of benzodiazepines on food intake were reported in 1960, when the agonist chlordiazepoxide was found to induce hyperphagia in both rats and dogs (Randall, 1960; Randall et al, 1960), and benzodiazepine hyperphagia was subsequently observed in other domestic and farm animals, primates and more recently, humans (Cooper, 2005). Subsequently, Cooper and coworkers, among others, showed that structurally diverse compounds with benzodiazepine site affinity bidirectionally modulate food intake according to their 
functional properties at the benzodiazepine receptor. That is, food intake is promoted not only by benzodiazepines, but also by nonbenzodiazepine compounds that act as full or partial benzodiazepine receptor agonists (Cooper, 1986; Cooper and Moores, 1985; Yerbury and Cooper, 1987; Chen et al, 1995), including some pyrazolopyridines, cyclopyrrolone derivatives, triazolopyridazines, pyrazoloquinolines, and $\beta$-carbolines. The orexigenic effects of such compounds are reversed by benzodiazepine antagonists, such as flumazenil (Ro 15-1788), and are not shared by stereoisomers that lack benzodiazepine receptor activity (for review, see Cooper, 2005). Conversely, compounds that are inverse agonists at the benzodiazepine receptor, including the imidazobenzodiazepines Ro 15-3505 and Ro 15-4513, some pyrazoloquinolines, and $\beta$-carbolines such as CGS 8216, DMCM, $\beta$-CMC and FG 7142, all reduce food intake (Cooper et al, 1985, 1989; Bernard et al, 1986; Patel and Ebenezer, 2002). These anorectic effects also are blocked by benzodiazepine receptor antagonists (Cooper, 2005).

Although the pharmacological specificity of benzodiazepine receptor ligands on food intake is clear, their behavioral mode of action remains uncertain. Some research has questioned the behavioral specificity of feeding effects, as they might reflect changes in arousal, perseveration (Hunt et al, 1988) or anxiolytic (eg behavior disinhibiting) and anxiogenic properties of benzodiazepine receptor agonists and inverse agonists, respectively (Cooper, 2005). However, the orexigenic activities of benzodiazepine receptor agonists are pharmacologically, neuroanatomically and molecularly dissociable from their sedative/hypnotic effects, and possibly also from their anxiolytic-like effects (Cooper, 2005).

Moreover, several findings have led to the alternative hypothesis that benzodiazepine receptor ligands modulate the positive evaluation of food (eg palatability) with inverse agonists dulling food's positive hedonic impact. For example, benzodiazepine receptor agonists increase break points for food reinforcement under progressive-ratio responding schedules, enhance opioid-dependent positive, but not negative, hedonic evaluations in taste reactivity tests, and facilitate food-reinforced incentive learning (Cooper, 2005; Richardson et al, 2005). Conversely, benzodiazepine receptor inverse agonists reduce preference for favored sweet and salty solutions and reduce sham intake of sucrose in gastric-fistulated rats (Cooper, 2005).

Microstructure analysis of prandial food and water intake in nondeprived subjects can help define the behavioral mode of action by which benzodiazepine receptor inverse agonists reduce food intake. Microstructure analyses of palatable food intake (Cooper and Yerbury, 1986a, b) and licking of palatable solutions (Higgs and Cooper, 1996, 1998) following benzodiazepine partial inverse agonist treatment were reported by Cooper and co-workers. However, those experiments did not analyze empirically validated and discriminated units of ingestion and only studied short-term intake (eg, $30 \mathrm{~min}$ ) in subjects without concurrent access to water (for feeding studies) or food (for licking studies). In rats, a novel meal microstructure definition recently showed that meals are integrated units of feeding and drinking (Zorrilla et al, 2005a,b). Using arbitrary or log-survivorship analysis of inter-feeding intervals to define meals, as has been done previously, can lead to invalid conclusions regarding the microstructure of ingestion (Zorrilla et al, 2005a,b). Meal definitions that account for prandial drinking allow the microstructure of prandial food and water intake to be studied (Zorrilla et al, 2005a; Tolkamp et al, 2000; Morgan et al, 2000). Meals identified in this way were followed by the behavioral satiety sequence and conformed to predictions of satiety (ie, a low initial probability of resuming feeding following meal termination which increases monotonically thereafter). In contrast, meal definitions based on arbitrary or logsurvivorship analysis of inter-ingestion intervals were not similarly validated and led to misguided conclusions regarding the effects of leptin and food deprivation on the microstructure of ingestion (Zorrilla et al, 2005a, b).

The present experiment, therefore, used the novel meal microstructure analysis to study the dose-related effects of systemic administration of the $\beta$-carboline FG 7142, a benzodiazepine receptor partial inverse agonist, on the microstructure of prandial intake in nondeprived rats consuming a palatable sweetened chow diet. Partly because of estrous cycle variability, males are disproportionately studied in biomedical research. However, stress-related disorders that involve changes in the hedonic evaluation of food, including bulimia and binge eating disorders (Lowe and Levine, 2005; Hinton et al, 2004; Sanchez Gomez et al, 2002), are much more prevalent in young women, a finding which compels more basic neuropharmacologic feeding research in females. Indeed, surprisingly little is known about the ingestive or stress-related effects of benzodiazepine receptor ligands in female rats, generally, as most studies have been performed in males. Therefore, subjects were young adult female rats studied during pharmacologically determined diestrus. The hypothesis that benzodiazepine inverse agonist anorexia is behaviorally nonspecific (eg, anxiogenic-like effects) predicts that FG 7142 would produce ingestive effects similar to those shared by $30-\mathrm{min}$ restraint stress in rats and mice and resident-intruder stress in rats, namely nonselective decreases in both food and water intake as a result of less and briefer intake of both food and water within meals. The behaviorally specific, food reward-modulating hypothesis of benzodiazepine inverse agonist anorexia predicts that FG 7142 would reduce food intake selectively and decrease average meal size as well as the regularity and rate of food intake within meals, microstructure effects opposite to those produced by increasingly palatable sweet tastants.

\section{MATERIALS AND METHODS}

\section{Subjects}

Adolescent female Wistar rats $(n=97,126-150 \mathrm{~g}, 41-47$ days old) were obtained from Charles River (Hollister, CA, USA) and group-housed on arrival in a 12:12 h lit $(0600 \mathrm{~h}$ lights on), humidity (60\%), and temperature-controlled $\left(22^{\circ} \mathrm{C}\right)$ vivarium. Rats had access to standard rodent chow (LM-485 Diet 7012; Harlan Teklad, Madison, WI, USA) and water ad libitum for 1 week before the start of experiments. Experimental procedures adhered to the National Institutes of Health Guide for the Care and Use of Laboratory Animals (NIH Publication number 85-23, revised 1996) and the 'Principles of laboratory animal care' (http://www.nap.edu/ 
readingroom/bookslabrats) and were approved by the Institutional Animal Care and Use Committee of The Scripps Research Institute.

\section{Drugs}

The gonadotropin-releasing hormone $(\mathrm{GnRH})$ superagonist [D-Try ${ }^{6}$, Pro $^{9}$-NEt]-GnRH was synthesized by solid-phase methodology (Rivier et al, 1974) and kindly gifted by Jean Rivier (The Clayton Foundation Laboratories for Peptide Biology, The Salk Institute, La Jolla, CA, USA). The peptide was freshly dissolved in $0.1 \mathrm{~N}$ acetic acid $(0.5 \mu \mathrm{g} / \mu \mathrm{l})$, and then diluted to the injected concentration in $1 \times \mathrm{PBS}$. FG 7142 ( $\beta$-carboline-3-carboxylic acid $N$-methylamide, Sigma, St Louis, MO, USA) and flumazenil (ethyl 8-fluoro-5, 6-dihydro-5-methyl-6-oxo-4H-imidazo $(1,4)$ benzodiazepine-3-carboxylate, Hoffman-La Roche Inc., NJ, USA) were dissolved in acidified $(\mathrm{pH}=5$ with $1 \mathrm{M} \mathrm{HCl}) 40 \%(\mathrm{w} / \mathrm{v})$ 2-hydroxypropyl- $\beta$-cyclodextrin (Sigma, St Louis, MO, USA). FG 7142, flumazenil and vehicle $(2 \mathrm{ml} / \mathrm{kg}$ when a single administration was given or $1 \mathrm{ml} / \mathrm{kg}$ each when two administrations were given) were injected intraperitoneally (i.p.).

\section{Microstructural Analysis of Ingestion}

Apparatus. To study the effects of FG 7142 on the microstructure of ingestion, rats were individually housed for $23 \mathrm{~h}$ each day in Plexiglas test cages $(22 \times 22 \times 35 \mathrm{~cm})$ equipped and validated for this purpose (Zorrilla et al, $2005 \mathrm{a}, \mathrm{b})$. Cages had a wire-mesh floor and were located in ventilated, sound-attenuating enclosures equipped with a $1.1 \mathrm{~W}$ bulb that provided a $12: 12 \mathrm{~h}$ light cycle with lights on at $0600 \mathrm{~h}$. Rats obtained individual chow pellets $(45 \mathrm{mg}$ precision food pellets, formula A/I; carbohydrate $65.5 \%$, fat $10.4 \%$, protein $24.1 \%, \mathrm{kcal} / \mathrm{g} \%, 370 \mathrm{kcal} / 100 \mathrm{~g}$, Research Diets Inc.) from a trough replenished by an automated dispenser (Med Associates, St Albans, VT). This diet consists of Purina 5001 chow supplemented with binders to facilitate pelleting, including $15 \%$ corn syrup (w/w). These pellets are relatively palatable, as adult male Wistar rats $(n=8)$ prefer them to Harlan Teklad LM-485 Diet 7012 (the diet previously available to subjects in the current study), in both 1 -h $(M \pm$ SEM: $93.9 \pm 7.1 \%)$ and 6-h free intake choice sessions $(89.1 \pm 4.3 \%)$. The acquisition of individual pellets was detected by photobeams that were broken ( $0.5 \mathrm{~s}$ duration) when the rat displaced a freely swinging door to access the pellet in the trough. An additional pellet was not delivered until the door returned to a neutral position and a $3.25 \mathrm{~s}$ timeout period had elapsed to prevent duplicate pellet deliveries (timeout based on ÉM Fekete and EP Zorrilla, unpublished observations of interpellet intervals), thereby allowing resolution of feeding at the unit of individual pellets. Water delivery $(0.1 \mathrm{ml})$ into a reservoir was governed by a response-contingent solenoid (WW Grainger, Lincolnshire, IL) that was activated by nosepoke interruption $(0.5 \mathrm{~s})$ of photobeams monitoring a separate hole, with a $1 \mathrm{~s}$ timeout period to prevent duplicate delivery. Responses were recorded automatically by an IBM PC-compatible microcomputer with $10 \mathrm{~ms}$ resolution. Spillage is low in this system $(1.2 \pm 0.2 \%$ of food responses; $n=105$ sessions) (Zorrilla et al, 2005a). The present procedures allow highly reliable study of spontaneous feeding and drinking with excellent quantitative and temporal resolution (Zorrilla et al, 2005a, b).

Behavioral testing. Female Wistar rats $(n=49)$ lived in the microstructure enclosures continuously except for brief periods $(30-60 \mathrm{~min})$ immediately prior to the onset of their dark cycle during which they were removed to permit maintenance and cleaning. Sessions began at $1800 \mathrm{~h}$. Testing began once food intake had stabilized $(<15 \%$ variation for initial 12-h food intake across 3 consecutive days).

To determine effects of FG 7142, a 2 (baseline $v s$ experimental $) \times 4$ (dose) mixed design was used in which dose of FG 7142 was a between-subjects factor $(n=8 /$ dose), and baseline (uninjected) vs experimental condition was a within-subjects factor. The baseline condition allows highly sensitive within-subjects comparisons (Zorrilla et al, 2005a) of FG 7142-induced changes in feeding by analysis of covariance (ANCOVA). To synchronize estrous cycling across rats and across baseline $v s$ experimental conditions, feeding-stabilized rats (70-76 days of age) were injected $(2 \mu \mathrm{g} / 200 \mu \mathrm{l} \mathrm{s.c.}), 3$ and $8 \mathrm{~h}$ into their dark cycle, with the potent GnRH receptor superagonist (D-Try ${ }^{6}$, Pro ${ }^{9}-\mathrm{NEt}$ )GnRH, a treatment schedule that entrains cycles which then follow a 4-day period (Rivier and Vale, 1990; Richardson et al, 2006). With this schedule, $>80 \%$ of rats reproducibly show cornified cells in vaginal lavage the following morning, and thereafter share entrained cycles (Rivier and Vale, 1990; Richardson et al, 2006). Pharmacological synchronization significantly reduces day-to-day and experimental error variance because subjects can be studied not only on a defined day of estrous, but also on a defined day of experimentation. The small minority of rats not entrained by this procedure would not differ systematically across treatment conditions and thereby constitute (reduced) noise, rather than bias. Vaginal lavage/smears were not performed to avoid stressful effects of this procedure (Sharp et al, 2003) and to avoid unintended potential effects of vaginocervical stimulation on feeding-relevant end points (Chan et al, 1984; Pfaus et al, 2000).

On the second day after injections, most rats $(>80 \%)$ are in diestrus I (metestrus), remaining synchronized. The second postinjection day (diestrus I, 72-78 days of age) was the baseline day, and the sixth day (the second cycle of diestrus I) was the experimental day. On the experimental day, rats were pretreated with FG $7142(0,3.75,7.5$, or $15 \mathrm{mg} /$ $\mathrm{kg}$ i.p.) at $1630 \mathrm{~h}$ ( $30 \mathrm{~min}$ before testing). Food and water intake were monitored as nosepoke responses for $12 \mathrm{~h}$.

To test the ability of flumazenil, a benzodiazepine receptor antagonist, to block the anorectic effects of FG 7142 , separate groups of females were studied, synchronized in diestrus $\mathrm{I}$ as described above. Rats were tested in a 2 (FG 7142: vehicle $v s 7.5 \mathrm{mg} / \mathrm{kg}$ ) $\times 2$ (Flumazenil: vehicle $v s$ $10 \mathrm{mg} / \mathrm{kg}$ ) mixed design. FG 7142 condition was a betweensubjects factor ( $n=8-9$ rats/group), and flumazenil treatment was a within-subjects factor, counterbalanced in order. Flumazenil condition was administered $10 \mathrm{~min}$ before FG 7142 condition, which was given $30 \mathrm{~min}$ before onset of food intake sessions.

Meal pattern analysis. Microstructure analysis used a meal definition that recognizes the existence of prandial 
drinking within meals (Zorrilla et al, 2005a). For this, log-transformed frequency histograms of the duration of consecutive (uninterrupted by drinking) inter-feeding intervals were constructed from nocturnal baseline data ( $n=4947$ inter-feeding intervals). The analysis revealed two distinct log-normal frequency distributions. The faster distribution putatively contains within-meal intervals and the slower distribution between-meal intervals. A value between the distributions ( $257 \mathrm{~s}$ between feeding or drinking events) was set as the meal 'breakpoint', or the time elapsed without intake at which a meal was considered to have ended. In a larger study of male rats ( $n=12393$ intervals), this procedure obtained the same threshold meal breakpoint that resulted from previously validated methodology (Zorrilla et al, 2005a). Parameters of average nocturnal meal structure were then calculated, including the number of meals; the average size, duration and response rate of meals; and the average inter-meal interval. Meal duration was calculated as the time elapsed from the first to last response of a meal, and duration of eating (or drinking) within the meal was calculated as the sum of the durations of uninterrupted bursts of eating (or drinking). Thus, transitions between eating and drinking were included in total meal duration, but not in the duration of eating or drinking. Meal sizes for eating and drinking were calculated separately as the average number of food or water-directed responses during meals. Rates of eating and drinking were calculated by dividing each meal size by its respective duration. The inter-meal interval was defined as the interval from the last response of a meal to the first response of the next meal. Because measures of meal duration reflect not only the time spent in the actual act of ingestion (ie, chewing, licking, swallowing), but also the quantity of intra-meal pausing, calculated measures of eating/drinking rate reflect whether ingestion was sustained by food or water within meals and not only the mechanical act of ingestion.

Within-meal microstructure analysis. To determine whether FG 7142 altered the regularity of sustained feeding within meals, which would indicate a change in the frequency and/or duration of pausing between pellets two analytical methods were used: (1) frequency histogram analysis of the log-transformed duration of consecutive (uninterrupted by drinking) within-meal inter-feeding intervals (IFI's), and (2) return map analysis of consecutive intra-meal IFI's. For frequency histogram analysis, the mean, $\mathrm{SD}$, skewness, kurtosis, and normalized histogram entropy of each subject's distribution was individually determined and then averaged across subjects. The normalized histogram entropy $(H)$ is a measure of categorical variability in the rate of ingestion (contrasted from SD, a measure of continuous variability) and was computed according to the following formula (Shannonand Weaver, 1949):

$$
H=-\frac{\sum_{i}^{n} p_{i} \log _{2}\left(p_{i}\right)}{\log _{2}(n)}
$$

$H$ is scaled between 0 and 1 , with the denominator determined by the number of possible bins in the histogram $(n)$ and the numerator a function of the proportion of observations that fall within a given histogram bin $\left(p_{i}\right)$. Minimal $(H=0)$ entropy occurs when all observations occur within a single histogram bin, whereas maximal entropy $(H=1)$ (maximal entropy) occurs when each histogram bin had an equal probability, or a flat uniform joint density distribution. To determine the specificity of within-meal changes in the rate and regularity of feeding, the identical analyses were performed on consecutive within-meal interdrinking intervals (IDI's). Histograms were constructed from log-transformed IFI or IDI durations that fell from 2.59 to $257 \mathrm{~s}$, which reflected bins centered on $e^{0.95}$ to $e^{5.55}$ with a bin width of $e^{0.2}$.

Return maps, or joint inter-event interval plots, are a nonlinear method of time series analysis that reveals the serial temporal organization of discrete events in time (Dekhuijzen and Bagust, 1996; Li and Huston, 2002; Szücs et al, 2003). For return map analysis, each log-transformed inter-feeding interval duration $\left(\mathrm{IFI}_{i}\right)$ in the time-series was scatterplotted against its subsequent inter-feeding interval duration $\left(\mathrm{IFI}_{i+1}\right)$ in a Cartesian plane. In such an analysis, increased irregularity of serial events is observed as an increased spread/diffuseness, of the return map, whereas regular and rhythmic events are observed as densely focused clusters of points. Therefore, to quantify the serial regularity of intake within meals, the SD of the spread of the return map from the cluster's centroid $(x, y)$ was calculated in both $x$ and $y$ dimensions. Joint probability density distributions were constructed from return maps and appear in gray scale format with darker shades indicating higher local probabilities. To determine the specificity of changes in the serial regularity of feeding, return map analysis also was performed on consecutive inter-drinking intervals $\left(\mathrm{IDI}_{i}\right.$ vs $\left.\mathrm{IDI}_{i+1}\right)$.

Elevated plus-maze test. To determine whether the duration of incremental anorexia could be attributed to concurrent anxiogenic-like effects of FG 7142, separate groups of rats were tested in the elevated plus-maze at one of three post-treatment delays. Female 72- to 78-day-old rats ( $n=8$ /group) were tested in a 2 (FG 7142: vehicle $v s$ $7.5 \mathrm{mg} / \mathrm{kg}$, i.p.) $\times 3$ (delay: $10 \mathrm{~min}, 2.5$ or $4.5 \mathrm{~h}$ after the $30 \mathrm{~min}$ pretreatment interval) between-subjects design, synchronized in diestrus I as described above. Each delay time point fell within the $6 \mathrm{~h}$ of incremental anorexia observed following FG 7142. Delays were chosen according to the time course of FG $7142(7.5 \mathrm{mg} / \mathrm{kg})$ hypodipsia, a putative marker of nonspecific effects of FG 7142 on ingestion. Specifically, FG 7142 significantly suppressed incremental water intake during the first meal $(+10 \mathrm{~min}$ time point) and through $2 \mathrm{~h}$, but not from the third to sixth hours $(2.5,4.5 \mathrm{~h}$ time points).

The elevated plus-maze apparatus was made of Plexiglas and consisted of four arms $(50 \mathrm{~cm}$ long $\times 10 \mathrm{~cm}$ wide): two had $40-\mathrm{cm}$ high dark walls (enclosed arms), and two had $0.5 \mathrm{~cm}$ high ledges (open arms). The maze was elevated to a height of $50 \mathrm{~cm}$. Open arms received only $1.5-2.0$ lux of illumination. Animals were habituated to the anteroom during handling on the day prior to testing. On the day of testing, rats were kept in the quiet, dark anteroom for at least $2 \mathrm{~h}$ before testing. White noise $(70 \mathrm{~dB})$ was present throughout habituation and testing.

For testing, rats were placed individually onto the center of the maze facing a closed arm and removed after a 5-min period. The apparatus was wiped clean with water and dried 
after each subject. The primary measures were the percent of total arm time directed towards the open arms (ie, $100 \times$ open $\mathrm{arm} /($ open $\mathrm{arm}+$ closed $\mathrm{arm}))$, a validated index of anxiety-related behavior (Fernandes and File, 1996) and the number of closed arm entries, a specific index of locomotor activity (Cruz et al, 1994). Supplementary measures included the time spent in the open or closed arms; center time; and the number of open arm, total arm, or center entries.

Statistical analysis. To determine the time course of the effects of FG 7142 on total intake, two-way repeatedmeasures (dose and time) ANOVAs were performed on the incremental intake of food and water during 1-h time bins. Cumulative intake functions were plotted, and subsequent microstructure analyses were limited to the time period during which the drug exerted incremental anorexia. For these ANCOVA analyses, dose was a between-subjects factor, and baseline average was a covariate. Linear contrasts were performed to determine whether a log-linear dose-dependent relation existed between FG 7142 treatment and the measure of ingestion. Measures of latency to the first meal, and first meal size, kurtosis, skewness and mean intake rate in frequency histogram analysis of within-meal inter-ingestion intervals were log-transformed to reduce significant heterogeneity of variance between treatment groups. Because transformations could not correct the heterogeneity of variance observed in first meal size, differences in the size of the first meal were analyzed by nonparametric analyses. $\chi^{2}$ analysis was used to test whether FG 7142-treated subjects ate less than the median meal size of vehicle-treated controls. In the antagonist reversal study, planned Bonferroni-corrected $t$-tests were used to (1) confirm anorectic effects of FG 7142 alone, (2) determine whether flumazenil significantly increased intake of FG 7142-treated rats to vehicle-treated levels, and (3) determine whether flumazenil at $10 \mathrm{mg} / \mathrm{kg}$ showed intrinsic activity on feeding (level of significance set at $p<0.016$ ). To allow detection of effects of FG 7142 on elevated plus maze behavior, $t$-tests were used to compare the effects of FG 7142 vs vehicle at each time point. For these latter comparisons, using more 'conservative' statistical analysis (ANOVA, alpha-correction) would have unacceptably increased the risk of type II error (false negatives) because we sought to rule out that concurrent anxiogenic-like behavior explained protracted anorexia.

For post hoc interpretation of effects having more than two levels, Newman-Keuls tests were used, and Student's paired $t$-tests were used for factors having only two levels. The software packages used were Systat 11.0 (SPSS, Chicago, IL, USA), SigmaPlot 9.0 (Systat Software Inc., Point Richmond, CA, USA), Orbital Spike 3.9 (Attila Szücs, http://www.blki.hu/szucs/OS3.html), Origin 7.5 (OriginLab, Northampton, MA, USA), and InStat 3.0 (GraphPad, San Diego, CA, USA).

\section{RESULTS}

\section{Time Course of Effects on Ingestion}

FG 7142 dose-dependently reduced how much food young adult female rats ate starting from the first postinjection hour (see Figure 1) (dose: $F(3,28)=3.32, p<0.05$ ). Time course analyses indicated that the incremental anorexia of FG 7142 was greatest during the first half of the observation period, so subsequent analyses were limited to the first six post-treatment hours. The lowest dose of FG 7142 that significantly reduced food intake in this time scale was $7.5 \mathrm{mg} / \mathrm{kg}$. Unlike for feeding, FG 7142 treatment did not significantly decrease how much water subjects drank in this analysis.

\section{Prandial $v s$ Nonprandial Intake}

Table 1 shows the effects of FG 7142 on how much and for how long food and water were consumed during the first $6 \mathrm{~h}$. Confirming the results obtained from the $12 \mathrm{~h}$ analysis, FG 7142 selectively affected food intake without reliably altering prandial or non-prandial water intake. FG 7142 $(7.5,15 \mathrm{mg} / \mathrm{kg})$ specifically reduced how much, but not for how long, food was eaten. The anorectic potency of FG 7142 to reduce food intake (6-33\%) was log-linearly dose-related (see Table 1).

\section{Meal Microstructure}

First meal. To determine the most acute effects of FG 7142 on prandial intake, first meal microstructure analysis was performed, as illustrated in Figure 2. FG 7142 delayed the onset of meal taking, especially in a subset of subjects (log-linear dose effect, $\mathrm{F}=3.99, p=0.056$; Levene's Test of heterogeneity, $\mathrm{F}(3,28)=4.29, p=0.01)$. For example, one subject in the $3.75 \mathrm{mg} / \mathrm{kg}$ group and four subjects in the $7.5 \mathrm{mg} / \mathrm{kg}$ group did not begin eating for at least $13.3 \mathrm{~min}$, or three control SDs longer than the vehicle mean $(p<0.05)$, and two subjects from the $15 \mathrm{mg} / \mathrm{kg}$ group did not begin eating for at least $44.3 \mathrm{~min}$, or $10 \mathrm{SDs}$ longer than the control mean $(p<0.0001)$.

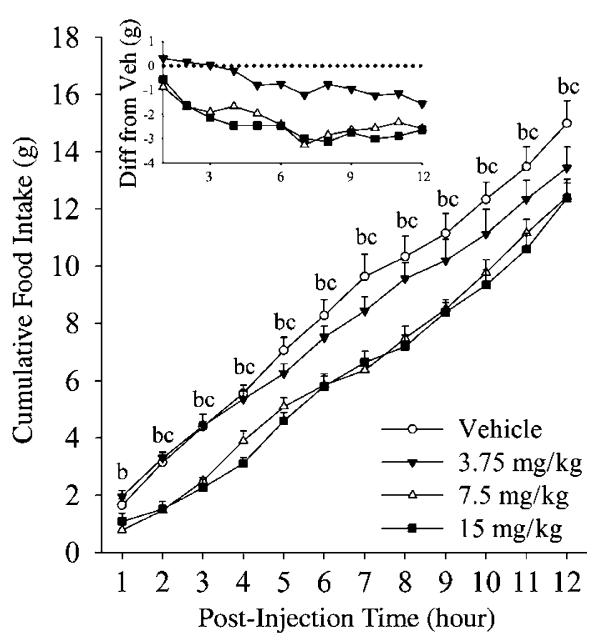

Figure I Effects of pretreatment with FG 7/42 (i.p. 30 min before testing) on mean $( \pm$ SEM) cumulative food intake in nondeprived, female Wistar rats $(n=32)$. Inset depicts mean difference from vehicle condition. Scale in inset differs from that of Figure I. Testing began at the onset of the dark cycle. Symbols denote significant differences of vehicle from (a) $3.75 \mathrm{mg} / \mathrm{kg}$, (b) $7.5 \mathrm{mg} / \mathrm{kg}$, (c) $15 \mathrm{mg} / \mathrm{kg}$ ( $p<0.05$, within-subjects NewmanKeuls test). 
Table I Effects of Intraperitoneal FG 7/42 on 6-h Intake in Female Rats

\begin{tabular}{|c|c|c|c|c|c|}
\hline Parameter & Baseline & \multicolumn{4}{|c|}{$\begin{array}{c}\text { Treatment day } \\
\text { Dose (i.p.) }\end{array}$} \\
\hline \multicolumn{6}{|l|}{ Feeding } \\
\hline Prandial intake $\left(\mathrm{g}^{\dagger \dagger \dagger}, \# \# \#\right)$ & $8.1 \pm 0.4$ & $8.3 \pm 0.5$ & $7.8 \pm 0.4$ & $5.7 \pm 0.3 * * * *$ & $5.6 \pm 0.4^{* * * *}$ \\
\hline \multicolumn{6}{|l|}{ Drinking } \\
\hline Total water intake (ml) & $16.5 \pm 1.0$ & $15.7 \pm 1.4$ & $16.0 \pm 3.7$ & $14.9 \pm 1.5$ & $13.2 \pm 1.8$ \\
\hline Prandial intake $(\mathrm{ml})$ & $13.0 \pm 0.9$ & $11.3 \pm 1.2$ & $12.2 \pm 3.5$ & $10.2 \pm 1.4$ & $10.6 \pm 1.8$ \\
\hline Nonprandial intake (ml) & $3.5 \pm 0.4$ & $4.4 \pm 0.7$ & $3.8 \pm 0.8$ & $4.7 \pm 0.6$ & $2.7 \pm 0.4$ \\
\hline Prandial duration (min) & $30.6 \pm 3.5$ & $30.2 \pm 4.7$ & $34 \pm 9.2$ & $23.3 \pm 3.2$ & $30.0 \pm 6.0$ \\
\hline
\end{tabular}

Effects of i.p. pretreatment ( $-30 \mathrm{~min}$ ) with FG 7/42 prior to the dark cycle on mean ( \pm SEM) quantity and duration of food and water intake in female Wistar rats $(n=32)$. Parameters were calculated for the first six postinjection hours, the period beyond which incremental anorexia was not observed. ${ }^{\# \# \#}$ Overall dose effect, $F(3,27)>9.03, p<0.001$. ${ }^{\dagger \dagger}$ Linear dose effect, $F(I, 27)>24.27, p<0.001$. **** $p<0.00$ I (between-subjects Newman-Keuls test).
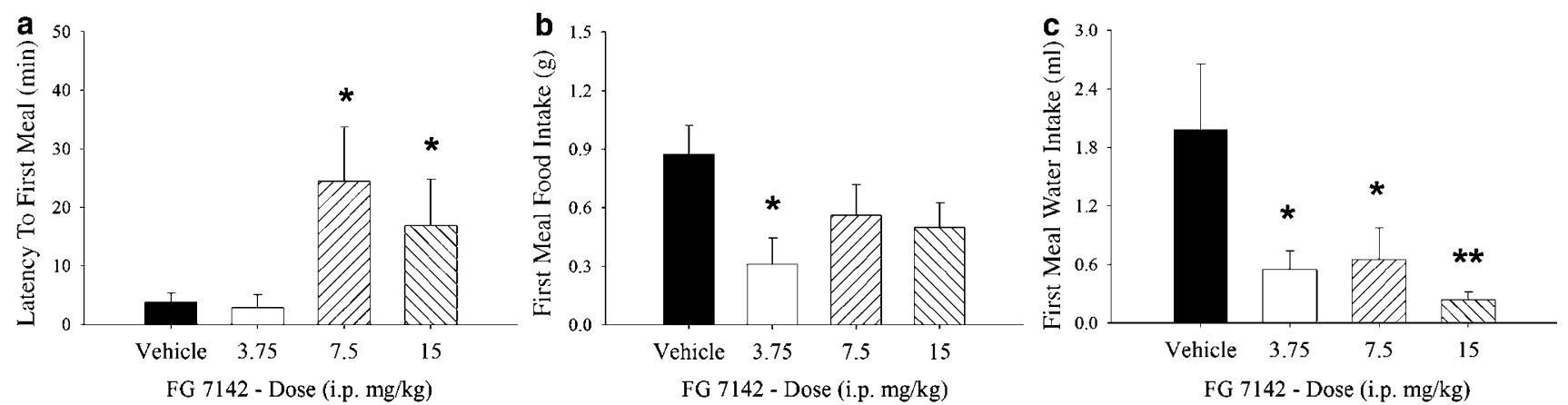

Figure 2 Effects of pretreatment with FG 7/42 (i.p. 30 min before testing) on mean ( \pm SEM) (a) latency (b) food intake, and (c) water intake of the first meal in female Wistar rats $(n=32)$. Symbols denote significant differences from vehicle: $* p<0.05, * * p<0.01$ (within-subjects Newman-Keuls test).

FG 7142 even more potently decreased how much was eaten (36-64\%; dose effect: $\mathrm{F}(3,27)=4.44, p<0.05)$ and drunk within the first meal $(63-87 \%$, overall dose effect: $F(3,27)=3.81, \quad p<0.05$; Log-linear dose effect: $\mathrm{F}(1,27)=8.59, p<0.005)$, with a minimum effective dose of $3.75 \mathrm{mg} / \mathrm{kg}$ or lower. Of all FG 7142-treated subjects, only four of $24(16.6 \%)$ ate more in the first meal than the median of vehicle-treated subjects $(0.675 \mathrm{~g})\left(\chi^{2}(1)=3.56, p<0.03\right)$. As shown in Table 2, FG 7142 also shortened the first meal by reducing the time spent drinking (59-87\%; log-linear dose effect: $\mathrm{F}(1,27)=5.64, p<0.05)$, without reducing the time spent eating or transitioning between eating and drinking (see Table 2). Finally, FG 7142 did not affect how much time passed between the first and second meal.

$6 \mathrm{~h}$ intake. To determine the mode of action by which FG 7142 continued to reduce intake across the active $6 \mathrm{~h}$ period of incremental anorexia, microstructure analysis was performed on this longer period. As shown in Figure 3, FG 7142 decreased cumulative $6 \mathrm{~h}$ food intake by dosedependently reducing how much food was eaten in a meal
(Figure 3a, overall dose effect: $\mathrm{F}(3,27)=3.94, p<0.05$; log-linear dose: $F(1,27)=11.75, p<0.01)$, rather than by reducing the frequency of meal-taking and increasing the time that passed between meals (Figure $3 \mathrm{~b}$ and $\mathrm{c}$ ). Even though FG 7142-treated rats ate smaller meals, their meals were of normal duration (Figure 3d), reflecting that they dose-dependently ate more slowly when eating (Figure $3 \mathrm{e}$, overall dose effect: $\mathrm{F}(3,27)=6.77, p<0.01$; log-linear dose: $\mathrm{F}(1,27)=19.82, p<0.001)$. The action of FG 7142 to make rats eat less and more slowly within meals was behaviorally specific, because the drug did not affect how fast (overall dose effect: $F(3,27)=0.19$, NS) or how much (overall dose effect: $F(3,27)=0.37$, NS) subjects drank within a meal. FG 7142 also did not affect for how long subjects drank within meals (data not shown).

In separate groups of rats, the protracted $(6 \mathrm{~h})$ anorectic effect of FG $7142(7.5 \mathrm{mg} / \mathrm{kg})(t(15)=-2.37, p<0.016)$ was fully blocked by the pretreatment with the benzodiazepine receptor antagonist flumazenil $(10 \mathrm{mg} / \mathrm{kg})(t(7)=-3.20$, $p<0.016)$ at a dose which did not intrinsically alter feeding $(t(15)=-0.17, p=0.432)$ (see Figure 4$)$. 
Table 2 Effects of Intraperitoneal FG 7/42 on First Meal Duration in Female Rats

Treatment day

Dose (i.p.)

\begin{tabular}{|c|c|c|c|c|c|}
\hline \multirow[b]{2}{*}{ Parameter } & \multirow[b]{2}{*}{ Baseline } & \\
\hline & & Vehicle & $3.75 \mathrm{mg} / \mathrm{kg}$ & $7.5 \mathrm{mg} / \mathrm{kg}$ & $15 \mathrm{mg} / \mathrm{kg}$ \\
\hline \multicolumn{6}{|l|}{ Meal duration (min) } \\
\hline Total & $14.3 \pm 1.8$ & $12.0 \pm 3.6$ & $8.2 \pm 2.5$ & $8.8 \pm 1.9$ & $8.8 \pm 2.5$ \\
\hline Drinking $^{\dagger}$ & $7.6 \pm 1.3$ & $6.6 \pm 2.5$ & $2.1 \pm 0.8$ & $2.9 \pm 1.5$ & $0.8 \pm 0.5^{*}$ \\
\hline Transition & $3.8 \pm 0.5$ & $2.5 \pm 1.0$ & $3.1 \pm 1.4$ & $3.3 \pm 1.0$ & $2.7 \pm 1.0$ \\
\hline
\end{tabular}

Effects of i.p. pretreatment $(-30 \mathrm{~min})$ with FG $7 \mathrm{I} 42$ before the dark cycle on mean $( \pm \mathrm{SEM})$ food and water duration of the first meal in female Wistar rats $(n=32)$. 'Linear dose effect, $F(I, 27)>5.64, p<0.05$. *Differs from vehicle, $p<0.05$ (between-subjects Newman-Keuls test).

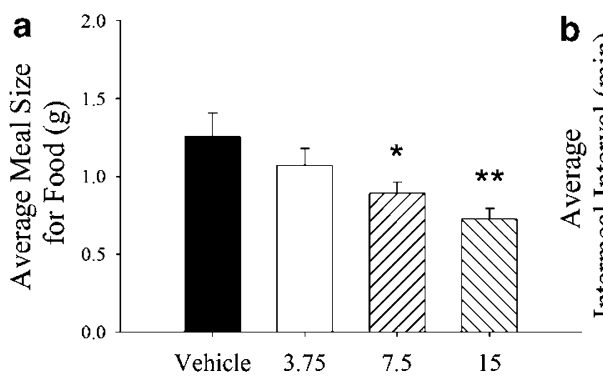

FG 7142 - Dose (i.p. $\mathrm{mg} / \mathrm{kg}$ )

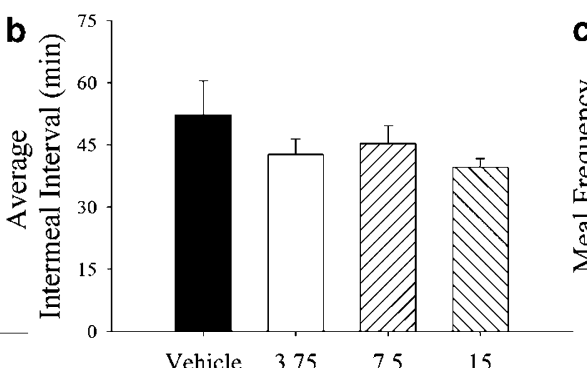

Vehicle $\quad 3.75 \quad 7.5 \quad 15$

FG 7142 - Dose (i.p. $\mathrm{mg} / \mathrm{kg}$ )

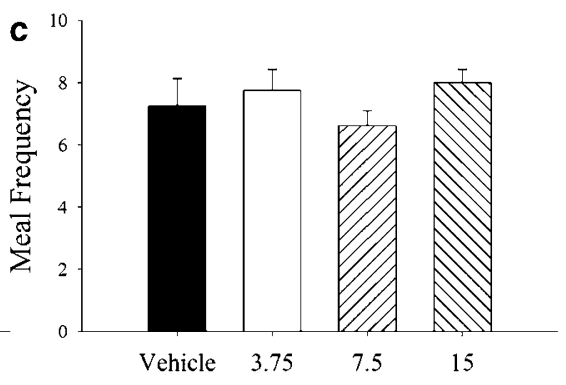

FG 7142 - Dose (i.p. $\mathrm{mg} / \mathrm{kg}$ )

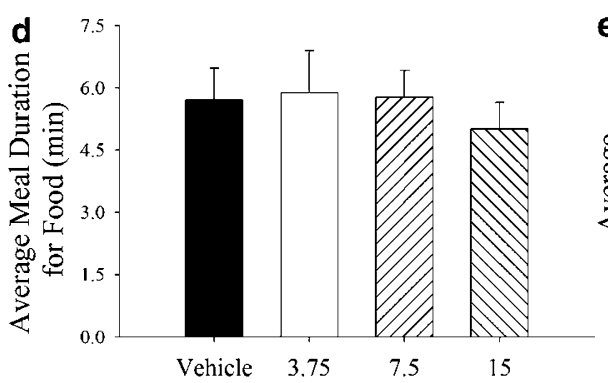

FG 7142 - Dose (i.p. $\mathrm{mg} / \mathrm{kg}$ )

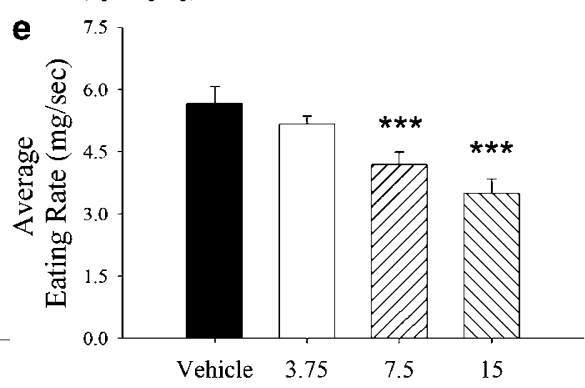

FG 7142 - Dose (i.p. mg/kg)

Figure 3 Effects of pretreatment with FG 7I 42 (i.p. 30 min before testing) on the mean ( \pm SEM) (a) average meal size, (b) average inter-meal interval, (c) meal frequency, $(d)$ average meal duration for food, and (e) eating rate for the first six postinjection hours, the period beyond which incremental anorexia was not observed. Subjects were female Wistar rats $(n=32)$. Symbols denote significant differences from vehicle: $* p<0.05$, $* * p<0.0$ l, $* * * *<<0.00$ I (within-subjects Newman-Keuls test).

\section{Rate and Regularity of Pellet-to-Pellet Intake within Meals}

As quantified in Table 4 and illustrated in Figures 5 and 6, within-meal analysis confirmed that FG 7142 dose-dependently reduced how fast subjects ate within bursts of consecutive feeding. This was quantified as an increase in the mean log-transformed duration of inter-feeding intervals and seen as (1) a shift to the right of the frequency histograms' central tendency (Figure 5), and (2) an upwardright shift of the return plot centroid (Figure $6 a$ and b).

However, FG 7142 not only slowed how quickly subjects ate on average, but also significantly decreased their regularity of eating within meals in a log-linear dosedependent fashion. That is, during bursts of feeding, food no longer maintained consistent rates of eating in FG 7142treated subjects, which paused increasingly and more variably between pellets. Decreased regularity was reflected

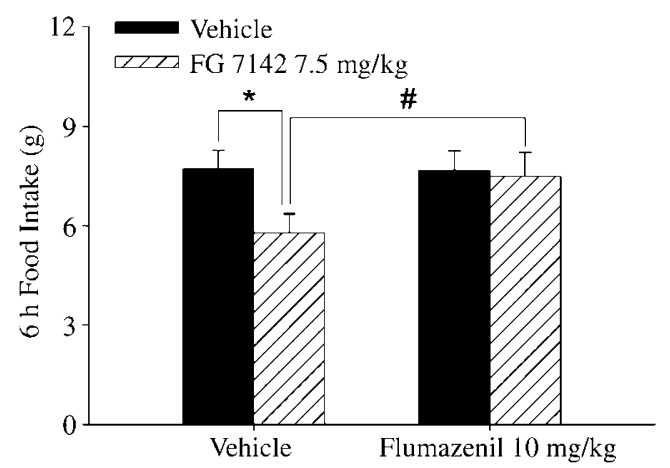

Figure 4 Effects of pretreatment with the benzodiazepine receptor antagonist flumazenil ( $10 \mathrm{mg} / \mathrm{kg}$, i.p. $40 \mathrm{~min}$ before testing) on the anorectic effect of FG $7142(7.5 \mathrm{mg} / \mathrm{kg}$, i.p. 30 min before testing) on mean ( \pm SEM) $6 \mathrm{~h}$ food intake in female Wistar rats $(n=18)$. Symbols denote significant differences: *from vehicle-vehicle condition, $p<0.016$, ${ }^{\#}$ from vehicle-FG $7 \mid 42$ condition, $p<0.016$ (Bonferroni-corrected $t$-tests). 

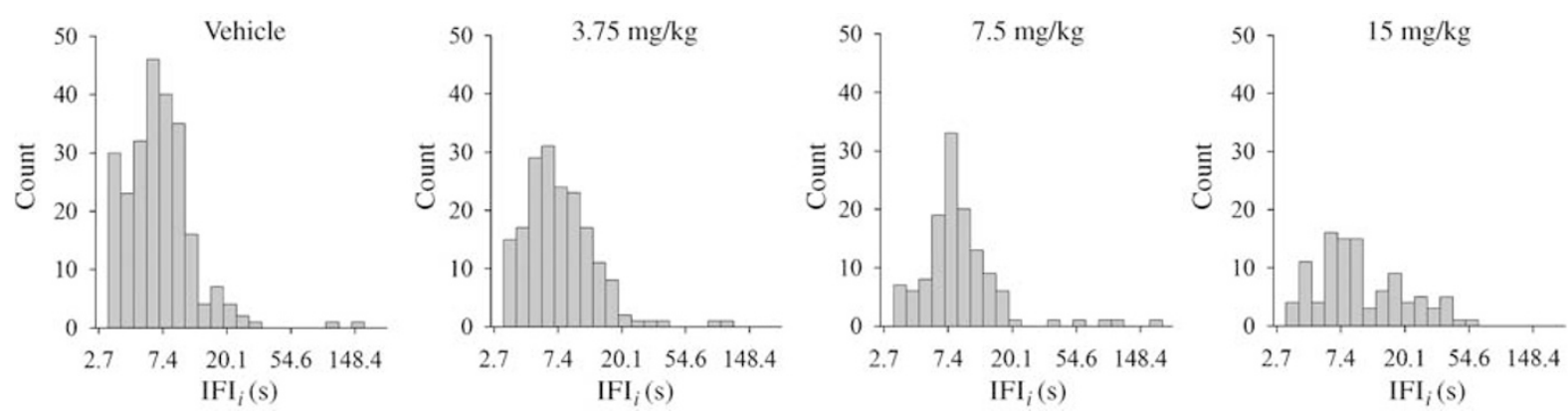

Figure 5 Effects of pretreatment with FG 7I 42 (i.p. 30 min before testing) on frequency histogram of the log-transformed duration of consecutive, intrameal inter-feeding intervals (IFI's) in female Wistar rats $(n=32)$. Frequency histograms were constructed from all of a subject's within-meal intervals as bins centered on 1.05 and 5.45 with a bin width of 0.2 (ie, $e^{0.95}$ to $e^{5.55}$, or 2.59-257s). The frequency histograms shown are from individual representative subjects.
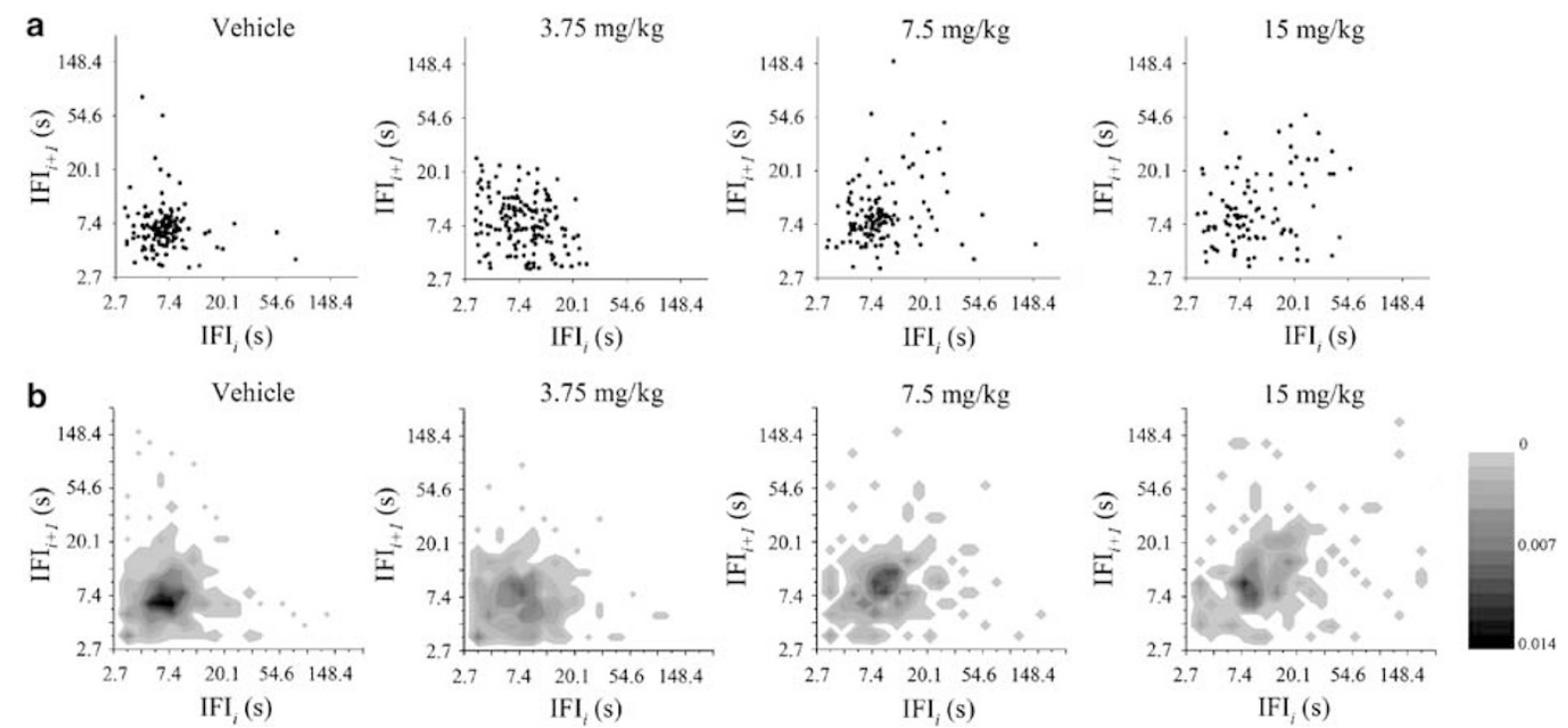

Figure 6 Effects of pretreatment with FG 7I 42 (i.p. 30 min before testing) on return map analysis of the log-transformed duration of successive intra-meal inter-feeding intervals (IFI's) that fell within bins centered on 1.05 and 5.45 with a bin width of 0.2 (ie, $e^{0.95}$ to $e^{5.55}$, or $2.59-257 \mathrm{~s}$ ) in female Wistar rats $(n=32)$. (a) Return map scatterplots of the individual IFl's of representative subjects. (b) Return map normalized probability density plots representing successive IFI's from all subjects ( $n$ 's $=8$ observations for each group). Each probability density function is comprised of 2025 (ie, $45^{2}$ ) bin spaces. Increasing gray-scale intensity (from white to dark) represents increasing probabilities (from 0 to 0.014 ) of successive eating events occurring at the corresponding IFI durations. Less spread and darker clusters indicate increased regularity of eating from pellet-to-pellet.

in frequency histograms as (1) a significant increase in the SD (a measure of continuous variability, reflected in the horizontal spread of the histogram), (2) a significant increase in the histogram entropy (a measure of categorical variability, reflected in an increasing number of populated histogram bins, each with more similar event frequencies), and (3) a significant decrease in the distribution's kurtosis (a measure of the distribution's 'peakedness', reflected in the flatter top and taller tails of the distribution). FG 7142 did not alter the right skew of the frequency histogram, a slight asymmetry that results from the natural and experimental floor for inter-feeding interval durations.

Return map analysis further showed that FG 7142 decreased the serial regularity of eating from pellet-topellet, illustrated as (1) an increased scatter and (2) lighter cluster shade in Figure 6a and b. Quantification of scatter from the centroid of individual return maps confirmed that FG 7142 increased the SD of serial feeding, again in a loglinear dose-dependent fashion (see Table 3). The findings reinforce that FG 7142-treated subjects increasingly paused between pellets of food and thereby did not maintain the typical pattern of sustained bursts of consistent and regular intake that results in an overall faster eating rate for vehicletreated rats.

Unlike for eating, FG 7142 did not influence the rate or regularity of sustained drinking within meals, as no reliable changes were observed in the relevant frequency histogram measures of prandial drinking (mean, SD, kurtosis, entropy) or in the return map scatterplot of serial drinking (see Table 3). Thus, FG 7142 specifically reduced the degree to which food maintained the behavioral focus of treated rats, reflected in a diminished rate and regularity of sustained feeding during the first six post-treatment hours.

\section{Elevated Plus-Maze Test}

As expected, FG $7142(7.5 \mathrm{mg} / \mathrm{kg})$ increased anxiogenic-like behavior in the plus-maze at the earliest delay time point 
Table 3 Effects of Intraperitoneal FG 7/42 on the Rate and Regularity of Food Pellet and Water Consumption within Meals

\begin{tabular}{|c|c|c|c|c|c|}
\hline Parameter & Baseline & \multicolumn{4}{|c|}{$\begin{array}{c}\text { Treatment day } \\
\text { Dose (i.p.) }\end{array}$} \\
\hline \multicolumn{6}{|c|}{ Food pellet consumption } \\
\hline \multicolumn{6}{|c|}{ Frequency histogram of inter-feeding interval duration } \\
\hline Skewness & $1.54 \pm 0.16$ & $1.54 \pm 0.32$ & $0.89 \pm 0.21$ & $1.44 \pm 0.16$ & $1.14 \pm 5.24$ \\
\hline Kurtosis & $9.48 \pm 0.93$ & $8.95 \pm 1.53$ & $5.73 \pm 1.02$ & $7.29 \pm 0.65$ & $5.24 \pm 0.50 *$ \\
\hline Entropy ${ }^{\dagger}$ \# & $0.62 \pm 0.01$ & $0.64 \pm 0.02$ & $0.70 \pm 0.01$ & $0.68 \pm 0.02$ & $0.73 \pm 0.02 *$ \\
\hline \multicolumn{6}{|c|}{ Water consumption } \\
\hline \multicolumn{6}{|c|}{ Frequency histogram of inter-drinking interval duration } \\
\hline Mean & $2.12(8.76) \pm 0.05$ & $2.21(9.65) \pm 0.13$ & $2.41(12.27) \pm 0.18$ & $1.98(7.44) \pm 0.08$ & $2.31(10.43) \pm 0.10$ \\
\hline SD & $0.90 \pm 0.03$ & $0.94 \pm 0.04$ & $0.90 \pm 0.09$ & $0.91 \pm 0.05$ & $1.03 \pm 0.06$ \\
\hline Skewness & $1.84 \pm 0.12$ & $1.77 \pm 0.26$ & $1.81 \pm 0.47$ & $2.06 \pm 0.14$ & $1.36 \pm 0.14$ \\
\hline Kurtosis & $6.29 \pm 0.65$ & $5.86 \pm 1.23$ & $7.93 \pm 3.40$ & $6.81 \pm 0.97$ & $3.92 \pm 0.49$ \\
\hline Entropy & $0.7 \mid \pm 0.02$ & $0.74 \pm 0.03$ & $0.75 \pm 0.05$ & $0.67 \pm 0.02$ & $0.74 \pm 0.03$ \\
\hline \multicolumn{6}{|c|}{ Return map of successive inter-drinking intervals } \\
\hline $\mathrm{SD} x$ & $0.89 \pm 0.03$ & $0.90 \pm 0.05$ & $0.95 \pm 0.08$ & $0.98 \pm 0.05$ & $0.84 \pm 0.07$ \\
\hline
\end{tabular}

Effects of i.p. pretreatment ( $-30 \mathrm{~min}$ ) with FG $7 / 42$ before the dark cycle on the temporal structure of feeding or drinking within meals as determined from frequency histogram and return map analysis. Data shown are mean $( \pm S E M)$ measures of the rate and regularity of feeding or drinking as reflected in the frequency histogram or return maps of the duration of within-meal interfeeding or interdrinking intervals in female Wistar rats $(n=32)$. Parameters are based on log-transformed (In(s)) interfeeding or interdrinking interval durations. Parenthetical values reflect backtransformed (sec) mean duration of interfeeding or interdrinking intervals. Parameters were calculated for the first six postinjection hours, the period beyond which incremental anorexia was not observed. ${ }^{\#}$ Overall dose effect, F(3, 27) $>3.0 \mathrm{I}$, $p<0.05$; ${ }^{\# \#}>5.84, p<0.01$. "Linear dose effect, $F(I, 27)>7.80, p<0.01,{ }^{\dagger \dagger}>11.49, p<0.001$. *Differs from vehicle, $p<0.05$; *** $p<0.0$ I; **** $p<0.00$ I (within-subjects Newman-Keuls test).

(10 min), evident as significant decreases in percent open arm time $(t(14)=-2.47, p<0.05)$, open arm time $(t(14)=-2.31, \quad p<0.05), \quad$ and open arm entries $(t(14)=-2.30, p<0.05)$ and increases in closed arm time $(t(14)=3.24, p<0.01)$ (see Table 4). FG 7142 also decreased measures of locomotor activity, including closed $(t(14)=-2.28, \quad p<0.05)$ and total arm entries $(t(14)=-2.28, p<0.05)$, and also decreased the time $(t(14)=-2.00, \quad p<0.05)$ and entries $(t(14)=-2.97$, $p<0.01)$ directed towards the center of the plus-maze.

At the later time points $(2.5 \mathrm{~h}, 4.5 \mathrm{~h})$, however, FG 7142 did not reliably affect any of the plus-maze measures, results that do not support the alternative hypothesis that concurrent anxiogenic-like behavior accounted for the $6 \mathrm{~h}$ of incremental anorexia (Table 4).

\section{DISCUSSION}

The main result of the present study is that FG 7142, a benzodiazepine inverse agonist, opposes the maintenance of sustained feeding within meals in female rats, reducing the rate and regularity of food intake and decreasing average meal size, effects opposite to those which result from increasing food palatability. Acute systemic administration of the $\beta$-carboline FG 7142 selectively and dose-dependently decreased palatable chow intake for $6 \mathrm{~h}$ in nondeprived female rats without suppressing concurrent cumulative water intake or producing similarly persistent anxiogeniclike behavior. Under a validated, objective and drinkinginclusive meal microstructure definition, FG 7142 deeply influenced the structure of feeding within meals, decreasing the rate and serial regularity of intake. In contrast, FG 7142 did not influence the distribution of meals across the day; meals were normal in length and satiety was normal in its persistence, as reflected in an unchanged postmeal interval and meal frequency. Thus, the primary anorectic mode of action of FG 7142 was to inhibit sustained eating within meals, resulting in smaller meals being eaten, while sparing the temporal pattern of meal-taking.

The anorectic actions of FG $7142(7.5 \mathrm{mg} / \mathrm{kg})$ were fully blocked by pretreatment with the specific benzodiazepine 
Table 4 Effects of Intraperitoneal FG $7142(7.5 \mathrm{mg} / \mathrm{kg})$ on Elevated Plus Maze Behavior in Female Rats

Time point

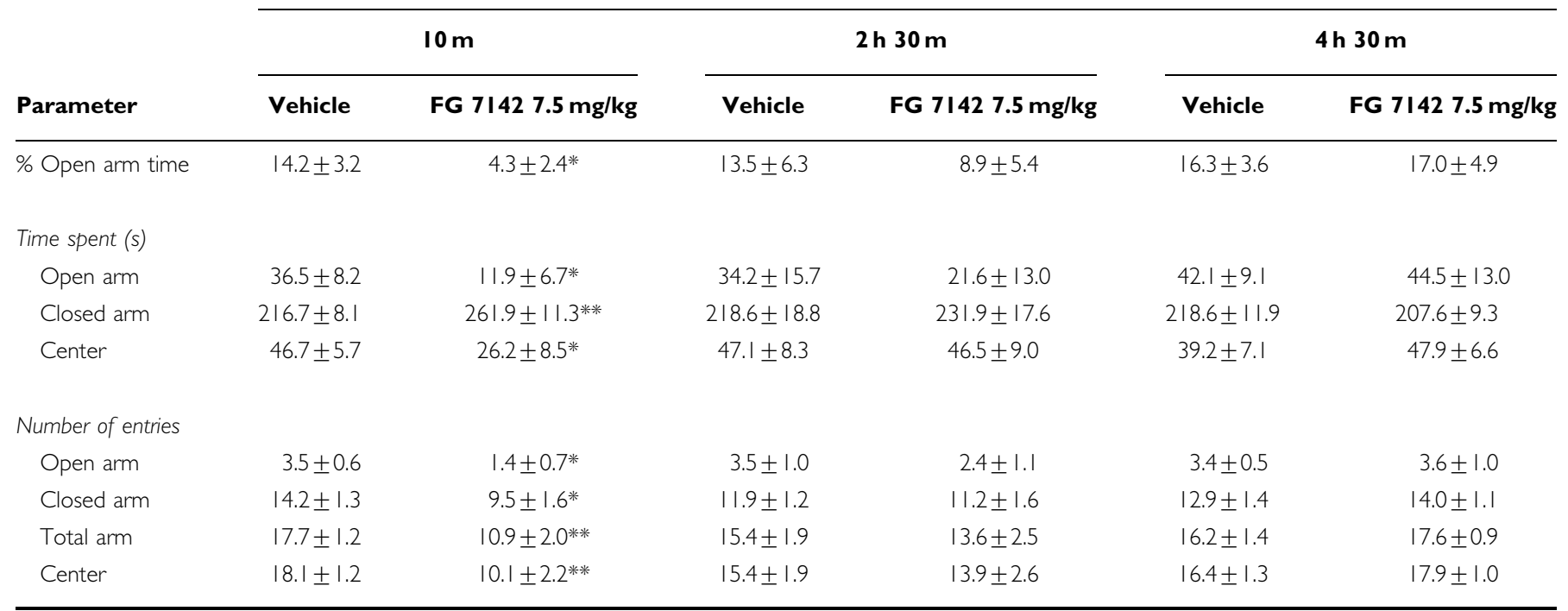

Effects of i.p. pretreatment ( $-30 \mathrm{~min}$ ) with FG 7142 (i.p. 0, $7.5 \mathrm{mg} / \mathrm{kg}$ ) prior to the dark cycle on elevated plus-maze behavior. Female Wistar rats $(n=48)$ were tested in a between-subjects design at one of three delay intervals from the end of pretreatment. Symbols denote significant differences: *from vehicle $p<0.05$; $* * * 0.0$ I (Student's t-test).

receptor antagonist flumazenil (10 $\mathrm{mg} / \mathrm{kg}$ ) (a $2: 1$ antagonist:agonist molar ratio), confirming a benzodiazepine receptor mode of action. At this dose, flumazenil did not show intrinsic activity on food intake.

FG 7142 decreased feeding selectively without altering how much water was drunk within or between meals and without changing how long subjects drank during the first six post-treatment hours. Furthermore, in contrast to the potent, dose-dependent effects of FG 7142 to reduce how fast and consistently subjects fed within meals, analogous measures of the rate and serial regularity of prandial drinking were unchanged. Previous studies reported a hypodipsic effect of FG 7142 (Cooper and Estall, 1985; Cooper et al, 1985; Mittleman et al, 1988) on deprivationinduced water consumption or schedule-induced polydipsia. However, these studies examined very brief time intervals $(\leqslant 30 \mathrm{~min})$. Despite different experimental conditions, the present data are consistent with prior findings since detailed analysis of the first nocturnal meal found that female rats treated with FG 7142 drank less water and spent less time drinking during the first meal. Thus, the $\beta$ carboline indiscriminately reduced both food and water intake immediately after injection, much like the effects of 30-min restraint or resident-intruder stress (Zorrilla, Tabarin and Koob, unpublished observations). However, only food intake remained altered during the whole 6-h period of incremental activity. Thus, the hypothesis that benzodiazepine inverse agonist anorexia is behaviorally nonspecific (eg, anxiogenic-like effects) only was supported for a very brief time interval. The main, persistent anorectic action of FG 7142 did not result from nonspecific behavioral suppression, but rather from highly specific effects on the maintenance of feeding within meals.

This 'behaviorally specific' interpretation of FG 7142 persistent anorexia was further supported by the timedependent effects of FG $7142(7.5 \mathrm{mg} / \mathrm{kg})$ on elevated plus- maze behavior. Specifically, a dose of FG 7142 that sustained incremental anorexia for at least $6 \mathrm{~h}(7.5 \mathrm{mg} / \mathrm{kg})$ significantly induced anxiogenic-like behavior only at the earliest time point tested (+10 min), when intake suppression was nonspecific. Although baseline levels of open arm exploration were somewhat low under the current experimental conditions, the acute anxiogenic-like action of FG 7142 could still be detected. A similarly high degree of anxiogenic-like activity was not seen at later time points, indicating a significant waning, if not absence, of treatmentinduced anxiogenic-like behavior by $2.5-4.5 \mathrm{~h}$ postadministration. Thus, concurrent, substantial anxiety was unlikely to account for the persistent duration of feeding suppression following FG 7142, but it cannot be excluded that prior anxiety initiated a cascade which led to more prolonged anorexia.

FG 7142 induced not only acute anxiogenic-like behavior, but also acute ( $10 \mathrm{~min}$ time point) reductions in plus-maze locomotor activity. Although reduced plus-maze locomotor activity might reflect increased freezing, the findings also raise the alternative interpretation that acute anti-ingestive effects of FG7142 reflect motor suppression rather than (or in addition to) anxiogenic-like behavior. However, several findings argue against the explanation that nonspecific motor suppression accounted for the persistent actions of FG 7142 on feeding behavior. First, the overall rate and regularity of drinking, unlike that for eating, was unaffected by FG 7142 pretreatment. Also, reductions in plus maze locomotor activity, like anxiogenic-like behavior, did not persist through the period of incremental anorexia; hypoactivity was no longer evident at later time points $(2.5 \mathrm{~h}, 4.5 \mathrm{~h})$.

To our knowledge, only one prior study (Cooper and Yerbury, 1986a) has attempted to examine the effect of a benzodiazepine receptor inverse agonist on the microstructure of food intake. However, differences in the meal 
definition ('bouts' defined arbitrarily and without regard to water intake) and experimental conditions (male $v s$ female rats, unavailability of water, $30 \mathrm{~min} v s 6 \mathrm{~h}$ ) make comparisons to the present study difficult. Nonetheless, it is interesting that the prior study also found that FG 7142 decreased the average eating rate. Suggesting bidirectionality of the action of benzodiazepine receptor ligands, the current findings are also consistent with a previous microstructure study of the ingestive effects of bretazenil (Clifton and Cooper, 1996), in which the benzodiazepine receptor agonist increased meal size without affecting meal frequency, meal duration or the inter-meal interval (Clifton and Cooper, 1996). Each of these studies is at odds with reports that the benzodiazepine receptor agonist midazolam increased palatable food consumption by increasing the time spent eating (Cooper and Yerbury, 1986a, b), although again the older findings may reflect a different unit or validity of microstructure analysis (empirically defined meals $v s$ arbitrarily defined bouts) or the previously mentioned procedural differences.

The $\beta$-carboline FG 7142 dose-dependently changed the temporal distribution of eating within sustained bursts of feeding, decreasing its sustained regularity. Rats paused longer on average between pellets, reflected in larger return map values in both the $x$ - and $y$-axes and a higher mean duration for the log-transformed inter-feeding interval frequency histogram. Eating also became less regular, reflected in an increased SD and entropy and decreased kurtosis of the frequency histogram (measures of continuous variability, categorical variability and peakedness, respectively). Importantly, the skewness of the frequency histogram was unchanged and the log-normal symmetry of eating intervals was retained, indicating that the control of eating per se was not disrupted. Increasing palatability (eg, a hybrid $3 \%$ glucose $+0.125 \%$ saccharin (w/v) as compared to a $3 \%$ glucose solution, or $0.125 \%$ saccharin solution) has the opposite effect on these measures of the rate and regularity of operant oral self-administration (M Mattock and EP Zorrilla, unpublished data). Thus, FG 7142 regularly, dosedependently and specifically disrupted the ability of food to sustain behavioral focus within meals, antipalatability-like effects on meal microstructure.

Table 5 compares the effect of FG 7142 on feeding microstructure with those of other anorectic drugs-naltrexone, fenfluramine, and leptin - as well as with psycho- social stressors that have been tested under the drinkinginclusive meal definition. Acute FG 7142, alone among the anorectic agents, specifically reduced food intake without altering water intake during the period of incremental anorexia. Unlike the satiety-like effects of leptin and certain stressors, FG 7142 preserved the structure of feeding between meals, leaving unchanged meal frequency and postmeal intervals (Zorrilla et al, 2005b; Zorrilla, Tabarin and Koob, unpublished observations). Unlike fenfluramine, which shortens the time spent eating as part of its meal terminating, pro-satiation effect, FG 7142 did not shorten meals, despite reducing how much was eaten within meals. That is, the effects of FG 7142 are less consistent with effects on the re-initiation or termination of feeding and more consistent with an effect on the maintenance of feeding. FG 7142 prevented food from sustaining a high, regular rate of intake within meals, such that animals had meals of normal duration, but that were smaller and eaten more slowly. Thus, the effects of FG 7142 on feeding microstructure more resemble the effects of a moderate dose of naltrexone $(1 \mathrm{mg} / \mathrm{kg})$ (Carrillo et al, 2001) an opioid receptor antagonist whose actions are proposed to result from decrements in the hedonic valuation of food (Cooper and Kirkham, 1993; Li et al, 2003; Kelley et al, 2000, 2005). Consistent with this parallel in the feeding microstructure mode of action of FG 7142 and naltrexone, recent taste reactivity studies likewise suggest similarity and cross-talk between opioid and GABAergic systems in modulating the hedonic impact of natural taste reward (Richardson et al, 2005). In addition, a very recent study that used a cyclic-ratio operant schedule paradigm similarly found that orexigenic properties of benzodiazepine receptor agonists appeared to be mediated through a mechanism affecting perceived palatability rather than through homeostatic, regulatory effects on food intake (O'Hare et al, 2006). The results emphasize similarities in the microstructure modes of action of a benzodiazepine receptor inverse agonist and opioid receptor antagonist to reduce food intake, but also indicate greater specificity of action by FG 7142, which did not modify total water drunk.

The $\mathrm{GABA}_{\mathrm{A}}$ receptor is putatively a pentamer comprising subunits of the $\mathrm{GABA}_{\mathrm{A}}$ receptor family, with most native receptors containing two $\alpha$, two $\beta$, and a single $\gamma$ subunit (Sieghart and Sperk, 2002). As a result the benzodiazepinebinding site occurs at the junction of the $\alpha$ and $\gamma$ subunits and because most native $\mathrm{GABA}_{\mathrm{A}}$ receptors contain the $\gamma 2$

Table 5 Comparison of the Effect of FG $7 / 42$ on Microstructure with Other Anorectic Agents

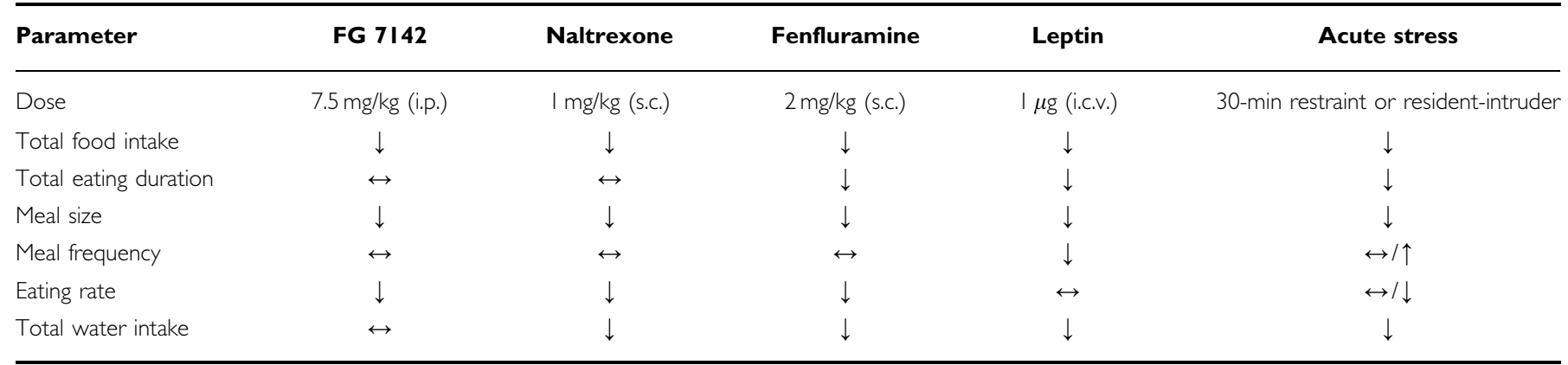

Comparison of the effect of FG 7/42 on feeding microstructure with those of other anorectic drugs (naltrexone, fenfluramine and leptin) as well as with psychosocial stressors (30-min restraint or resident-intruder) that have been tested in the validated drinking-inclusive meal definition (Zorrilla et al, $2005 a)$. 
subunit, benzodiazepine ligand pharmacology at $\mathrm{GABA}_{\mathrm{A}}$ receptors is mainly determined by the $\alpha$ subunits. In general, benzodiazepines interact with $\mathrm{GABA}_{\mathrm{A}}$ receptors that contain a $\beta$ and $\gamma 2$ subunit in association with $\alpha 1, \alpha 2$, $\alpha 3$, or $\alpha 5$ subunits, but not $\alpha 4$ or $\alpha 6$ subunits. Recently, it was proposed that $\alpha 2 / \alpha 3$ subunit-containing $\mathrm{GABA}_{\mathrm{A}}$ receptors are the receptor populations involved in the specific control of food intake behavior (Cooper, 2005). The present results are partly consistent with this hypothesis as FG 7142 is a much more potent inverse agonist at $\alpha 2$ subunitcontaining $\mathrm{GABA}_{\mathrm{A}}$ receptors $\left(\mathrm{EC}_{50}=5.9 \mathrm{nM}\right)$ than at $\alpha 5$ or $\alpha 3$ subunit-containing isoforms $\left(\mathrm{EC}_{50}=1439\right.$ and $1020 \mathrm{nM}$, respectively), although it ultimately has similar efficacy at each (Dawson et al, 2005). Future studies that compare ligands with subunit-selective inverse agonist efficacy at $\alpha 2$ subunit-containing receptors as opposed to those with preferential $\alpha 1, \alpha 3$, or $\alpha 5$ intrinsic efficacy could further define the role of $\alpha 2$-containing $\mathrm{GABA}_{\mathrm{A}}$ receptors in controlling the rate and regularity of sustained feeding. To the degree that $\alpha 1, \alpha 3$, and $\alpha 5$ subunit-containing $\mathrm{GABA}_{\mathrm{A}}$ receptors, respectively, mediate sedative/proconvulsant, anxiety-related and cognitive actions of benzodiazepine receptor ligands (Dawson et al, 2005), a selective $\alpha 2$-subunit inverse agonist perhaps could be useful in treating forms of overeating characterized by high, sustained rates of eating, including some forms of binge eating.

\section{ACKNOWLEDGEMENTS}

This is manuscript 18047 from The Scripps Research Institute. We gratefully recognize the editorial assistance of Mike Arends, the technical assistance of Bob Lintz, and the scholarly input of $\mathrm{Dr}$ Brendan Walker and two anonymous reviewers. This research was supported by DK64871 from the National Institute of Diabetes and Digestive and Kidney Diseases.

\section{REFERENCES}

Bernard PS, Pastor G, Liebman JM (1986). CGS 8216, a benzodiazepine antagonist, reduces food intake in food-deprived rats. Pharmacol Biochem Behav 24: 1703-1706.

Carrillo CA, Zorrilla EP, Koob GF (2001). The effects of naltrexone, a non-selective opiate receptor antagonist, on the consumption of sweetened food and solutions. AAAS Annual Meeting \& Science Innovation Exposition, San Francisco, 167, abstr\# A85.

Chan A, Dudley CA, Moss RL (1984). Hormonal and chemical modulation of ventromedial hypothalamic neurons responsive to vaginocervical stimulation. Neuroendocrinology 38: 328-336.

Chen SW, Davies MF, Loew GH (1995). Food palatability and hunger modulated effects of CGS 9896 and CGS 8216 on food intake. Pharmacol Biochem Behav 51: 499-503.

Chouinard G (2004). Issues in the clinical use of benzodiazepines: potency, withdrawal, and rebound. J Clin Psychiatry 65(Suppl 5): 7-12.

Clifton PG, Cooper SJ (1996). The benzodiazepine partial receptor agonist, bretazenil, provokes a strong hyperphagic response: a meal pattern analysis in free feeding rats. Behav Pharmacol 7: 454-461.

Cooper SJ (1986). Hyperphagic and anorectic effects of betacarbolines in a palatable food consumption test: comparisons with triazolam and quazepam. Eur J Pharmacol 120: 257-265.
Cooper SJ (2005). Palatability-dependent appetite and benzodiazepines: new directions from the pharmacology of $\operatorname{GABA}(\mathrm{A})$ receptor subtypes. Appetite 44: 133-150.

Cooper SJ, Barber DJ, Gilbert DB, Moores WR (1985). Benzodiazepine receptor ligands and the consumption of a highly palatable diet in non-deprived male rats. Psychopharmacology (Berlin) 86: 348-355.

Cooper SJ, Bowyer DM, Van der Hoek G (1989). Effects of the imidazobenzodiazepine Ro 15-4513 on saccharin choice and acceptance, and on food intake, in the rat. Brain Res 494: 172-176.

Cooper SJ, Estall LB (1985). Behavioural pharmacology of food, water and salt intake in relation to drug actions at benzodiazepine receptors. Neurosci Biobehav Rev 9: 5-19.

Cooper SJ, Kirkham TC (1993). Opioid mechanisms in the control of food consumption and taste preferences. In: Herz A (ed). Handbook of Experimental Pharmacology: II. Opioids II, Vol. 104. Springer-Verlag: Berlin. pp 239-262.

Cooper SJ, Moores WR (1985). Chlordiazepoxide-induced hyperphagia in non-food-deprived rats: effects of Ro15-1788, CGS 8216 and ZK 93 426. Eur J Pharmacol 112: 39-45.

Cooper SJ, Yerbury RE (1986a). Midazolam-induced hyperphagia and FG 7142-induced anorexia: behavioural characteristics in the rat. Pharmacol Biochem Behav 25: 99-106.

Cooper SJ, Yerbury RE (1986b). Benzodiazepine-induced hyperphagia: stereospecificity and antagonism by pyrazoloquinolines, CGS 9895 and CGS 9896. Psychopharmacology (Berlin) 89: 462-466.

Cruz AP, Frei F, Graeff FG (1994). Ethopharmacological analysis of rat behavior on the elevated plus-maze. Pharmacol Biochem Behav 49: 171-176.

Dawson GR, Maubach KA, Collinson N, Cobain M, Everitt B, Macleod A et al (2005). An inverse agonist selective for \{alpha\}5 subunit-containing GABAA receptors enhances cognition. J Pharmacol Exp Ther 316: 1335-1345.

Dekhuijzen AJ, Bagust J (1996). Analysis of neural bursting: nonrhythmic and rhythmic activity in isolated spinal cord. J Neurosci Methods 67: 141-147.

Fernandes C, File SE (1996). The influence of open arm ledges and maze experience in the elevated plus-maze. Pharmacol Biochem Behav 54: 31-40.

Higgs S, Cooper SJ (1996). Effects of the benzodiazepine receptor inverse agonist Ro 15-4513 on the ingestion of sucrose and sodium saccharin solutions: a microstructural analysis of licking behavior. Behav Neurosci 110: 559-566.

Higgs S, Cooper SJ (1998). Effects of benzodiazepine receptor ligands on the ingestion of sucrose, intralipid, and maltodextrin: an investigation using a microstructural analysis of licking behavior in a brief contact test. Behav Neurosci 112: 447-457.

Hinton EC, Parkinson JA, Holland AJ, Arana FS, Roberts AC, Owen AM (2004). Neural contributions to the motivational control of appetite in humans. Eur J Neurosci 20: 1411-1418.

Hunt T, Poulos CX, Cappell H (1988). Benzodiazepine-induced hyperphagia: a test of the hunger-mimetic model. Pharmacol Biochem Behav 30: 515-518.

Kelley AE, Bakshi VP, Fleming S, Holahan MR (2000). A pharmacological analysis of the substrates underlying conditioned feeding induced by repeated opioid stimulation of the nucleus accumbens. Neuropsychopharmacology 23: 455-467.

Kelley AE, Baldo BA, Pratt WE, Will MJ (2005). Corticostriatalhypothalamic circuitry and food motivation: integration of energy, action and reward. Physiol Behav 86: 773-795.

Li CS, Davis BJ, Smith DV (2003). Opioid modulation of taste responses in the nucleus of the solitary tract. Brain Res 965: 21-34.

Li JS, Huston JP (2002). Non-linear dynamics of operant behavior: a new approach via the extended return map. Rev Neurosci 13 31-57. 
Lowe MR, Levine AS (2005). Eating motives and the controversy over dieting: eating less than needed versus less than wanted. Obes Res 13: 797-806.

Mittleman G, Jones GH, Robbins TW (1988). Effects of diazepam, FG-7142, and Ro-15-1788 on schedule-induced-polydipsia and the temporal control of behavior. Psychopharmacology 94: 103-109.

Morgan CA, Emmans GC, Tolkamp BJ, Kyriazakis I (2000). Analysis of the feeding behavior of pigs using different models. Physiol Behav 68: 395-403.

O'Brien CP (2005). Benzodiazepine use, abuse, and dependence. J Clin Psychiatry 66(Suppl 2): 28-33.

O'hare E, Kim EM, Tierney KJ (2006). An operant determination of the behavioral mechanism of benzodiazepine enhancement of food intake. Psychopharmacology (Berlin) 187: 138-142.

Patel SM, Ebenezer IS (2002). The effects of the benzodiazepine receptor ligand 3-(methoxycarbonyl) amino-beta-carboline on food and water intake in rats. Methods Find Exp Clin Pharmacol 24: 681-683.

Pfaus JG, Smith WJ, Byrne N, Stephens G (2000). Appetitive and consummatory sexual behaviors of female rats in bilevel chambers. II. Patterns of estrus termination following vaginocervical stimulation. Horm Behav 37: 96-107.

Randall LO (1960). Pharmacology of methaminodiazepoxide. Dis Nerv Syst 21(Suppl 3): 7-10.

Randall LO, Schallek W, Heise GA, Keith EF, Badgon RE (1960). The psychosedative properties of methaminodiazepoxide. J Pharmacol Exp Ther 129: 163-171.

Richardson DK, Reynolds SM, Cooper SJ, Berridge KC (2005). Endogenous opioids are necessary for benzodiazepine palatability enhancement: naltrexone blocks diazepam-induced increase of sucrose-'liking'. Pharmacol Biochem Behav 81: 657-663.

Richardson HN, Zorrilla EP, Mandyam CD, Rivier CL (2006). Exposure to repetitive versus varied stress during prenatal development generates two distinct anxiogenic and neuroendocrine profiles in adulthood. Endocrinology 147: 2506-2517.

Rivier C, Vale W (1990). Cytokines act within the brain to inhibit luteinizing hormone secretion and ovulation in the rat. Endocrinology 127: 849-856.
Rivier J, Amoss M, Rivier C, Vale W (1974). Synthetic luteinizing hormone releasing factor. Short chain analogs. J Med Chem 17: 230-233.

Rudolph U, Möhler H (2004). Analysis of GABAA receptor function and dissection of the pharmacology of benzodiazepines and general anesthetics through mouse genetics. Annu Rev Pharmacol Toxicol 44: 475-498.

Sanchez Gomez PP, Troop NA, Treasure JL (2002). Psychophysiology and eating disorders. In: D'Haenen $\mathrm{H}$, den Boer JA, Willner P (eds). Biological Psychiatry. John Wiley \& Sons, Ltd: Chichester. pp 1159-1165.

Shannon CE, Weaver W (1949). The Mathematical Theory of Communication. University of Illinois Press: Urbana.

Sharp J, Zammit T, Azar T, Lawson D (2003). Stress-like responses to common procedures in individually and group-housed female rats. Contemp Top Lab Anim Sci 42: 9-18.

Sieghart W, Sperk G (2002). Subunit composition, distribution and function of GABA(A) receptor subtypes. Curr Top Med Chem 2: 795-816.

Szücs A, Pinto RD, Rabinovich MI, Abarbanel HD, Selverston AI (2003). Synaptic modulation of the interspike interval signatures of bursting pyloric neurons. J Neurophysiol 89: 1363-1377.

Tolkamp BJ, Schweitzer DPN, Kyriazakis I (2000). The biologically relevant unit for the analysis of short-term feeding behavior of dairy cows. J Dairy Sci 83: 2057-2068.

Yerbury RE, Cooper SJ (1987). The benzodiazepine partial agonists, Ro16-6028 and Ro17-1812, increase palatable food consumption in nondeprived rats. Pharmacol Biochem Behav 28: 427-431.

Zorrilla EP, Inoue K, Fekete EM, Tabarin A, Valdez GR, Koob GF (2005a). Measuring meals: structure of prandial food and water intake of rats. Am J Physiol Regul Integr Comp Physiol 288: R1450-R1467.

Zorrilla EP, Inoue K, Valdez GR, Tabarin A, Koob GF (2005b). Leptin and post-prandial satiety: acute central leptin more potently reduces meal frequency than meal size in the rat. Psychopharmacology 177: 324-335. 